2. Modlin IM, Sandor A. An analysis of 8305 cases of carcinoid tumors. Cancer. 1997;79:813-29.

3. Pandya UH, Pellikka PA, Enriquez-Sarano M, Edwards WD, Schaff HV, Connolly HM. Metastatic carcinoid tumor to the heart: echocardiographic-pathologic study of 11 patients. J Am Coll Cardiol. 2002;40:1328-32.
4. Weingarten TN, Abel MD, Connolly HM, Schroeder DR, Schaff HV. Intraoperative management of patients with carcinoid heart disease having valvular surgery: a review of one hundred consecutive cases. Anesth Analg. 2007;105: 1192-9.

\title{
Use of a hybrid operating room to diagnose and treat delayed coronary spasm after mitral valve repair
}

\author{
Jared L. Antevil, MD, Alexandros N. Karavas, MD, John H. Selby, MD, and John G. Byrne, MD, \\ Nashville, Tenn
}

We describe a case of delayed circulatory collapse after mitral valve repair caused by diffuse coronary artery vasospasm. The cause and management of this condition are discussed.

\section{CLINICAL SUMMARY}

A 66-year-old woman presented with severe symptomatic mitral valve regurgitation. Although cardiac catheterization revealed no significant epicardial coronary artery disease, the patient was taking long-acting oral nitrates and calcium antagonists for recurrent nonexertional chest pain and a presumed diagnosis of variant angina. At the time of the operation, inspection of the mitral valve revealed myxomatous characteristics with a redundant posterior leaflet, an associated posterior leaflet cleft, and override of the anterior leaflet. Repair was performed by using primary suture closure of the cleft, followed by annuloplasty with a 30-mm CosgroveEdwards device (Edwards Lifesciences, Irvine, Calif). A postrepair transesophageal echocardiogram revealed trivial residual mitral valve regurgitation and preserved biventricular function, without significant transmitral or subaortic gradients.

The patient was off all vasoactive medications (which included norepinephrine) within 3 hours of her operation and was extubated uneventfully that afternoon. Shortly after mediastinal tube removal the following day (28 hours postoperatively), she experienced chest pain and a precipitous decrease in her systolic blood pressure to $60 \mathrm{~mm} \mathrm{Hg}$. Her cardiac index decreased to $0.7 \mathrm{~L} \mathrm{~min}^{-1} \mathrm{~m}^{-2}$, and her central venous pressure of $23 \mathrm{~mm} \mathrm{Hg}$ was identical to her diastolic pulmonary artery pressure.

\footnotetext{
From the Vanderbilt Heart and Vascular Institute, Nashville, Tenn. Disclosures: None.

Received for publication June 10, 2009; revisions received July 14, 2009; accepted for publication July 31, 2009; available ahead of print Sept 27, 2009.

Address for reprints: John G. Byrne, MD, Vanderbilt University Medical Center, Nashville, TN 37232-8802 (E-mail: john.byrne@vanderbilt.edu).

J Thorac Cardiovasc Surg 2010;140:e25-7

$0022-5223 / \$ 36.00$

Copyright (C) 2010 by The American Association for Thoracic Surgery

doi:10.1016/j.jtcvs.2009.07.074
}

Surface echocardiographic analysis during preparations to reopen her chest for suspected tamponade revealed severe global hypokinesis of both ventricles, with a left ventricular ejection fraction of less than $10 \%$. The patient's mitral valve repair appeared to be intact. Mediastinal exploration revealed no evidence of bleeding, tamponade, or other surgical complications. She was taken on an emergency basis to the hybrid operating room-catheterization laboratory for further evaluation and treatment. The diagnoses of left circumflex coronary artery injury or coronary thrombus were entertained. The patient was supported with intravenous infusions of epinephrine, dopamine, and norepinephrine en route to the hybrid operating room.

Open-chest intraoperative coronary angiographic analysis was initiated, but engagement of the left coronary artery resulted in pressure dampening and a sudden decrease in blood pressure. After placement of a femoral intra-aortic balloon pump (IABP), coronary angiographic analysis revealed diffuse severe stenosis of the left anterior descending and right coronary arteries, which is consistent with coronary vasospasm (Figure 1). With intracoronary nitroglycerin infusion into both the left and right coronary systems and a reduction in the patient's adrenergic medications, the patient's vasospasm improved but did not completely resolve. Infusions of milrinone and nitroglycerin were initiated, the patient's norepinephrine was weaned to $5 \mu \mathrm{g} / \mathrm{min}$, and her chest was closed.

Over the next week, the patient demonstrated steady hemodynamic improvement. Repeated echocardiograms demonstrated normalization of biventricular function, and her IABP was removed 4 days after her reoperation. The patient was restarted on a long-acting oral nitrate and calcium antagonist. She was discharged home 20 days after her original operation and has been free of dyspnea and angina to date.

\section{DISCUSSION}

Although it is likely underrecognized, clinically significant coronary vasospasm has been reported to occur after 


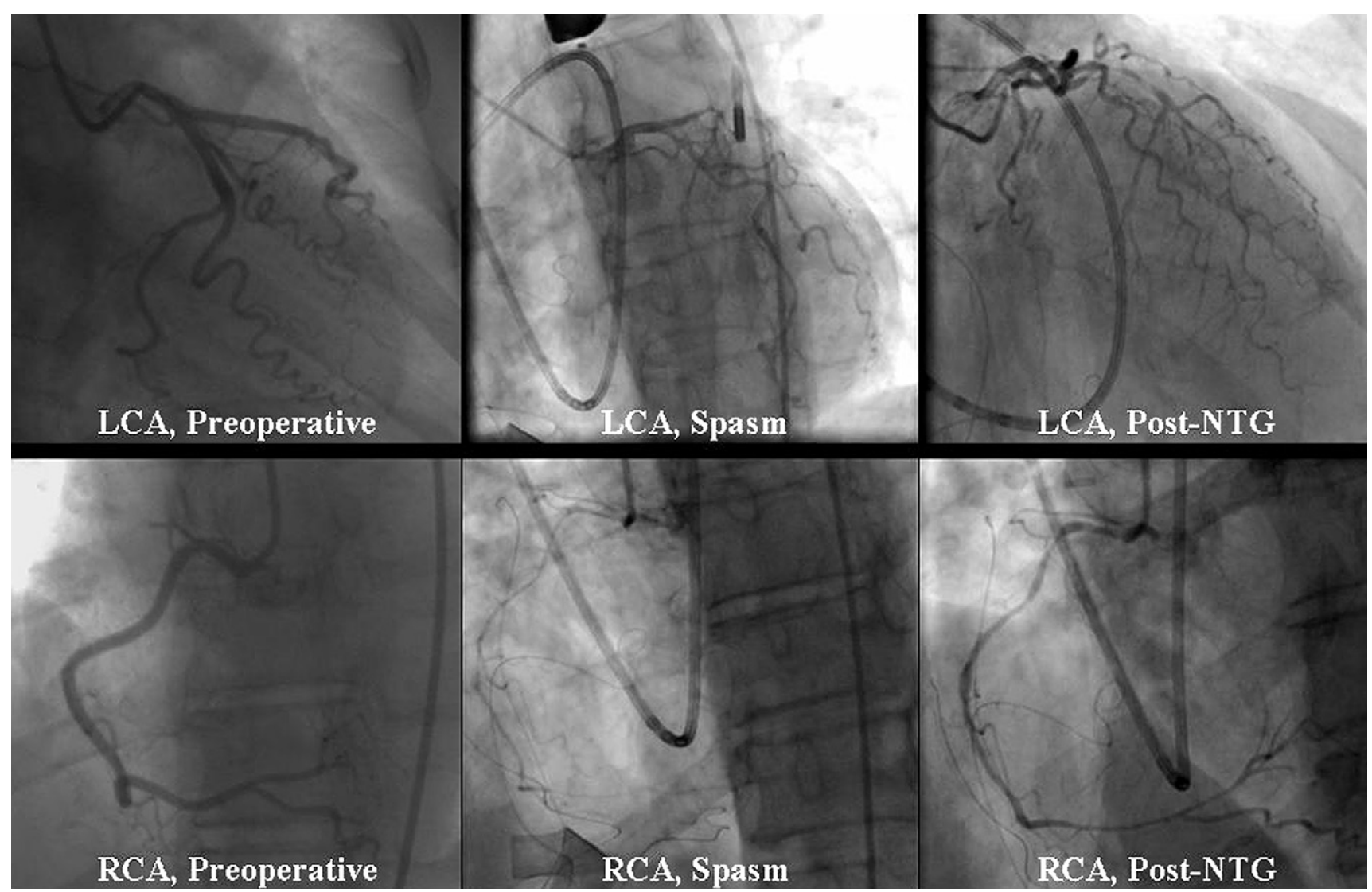

FIGURE 1. Left coronary artery $(L C A)$ and right coronary artery $(R C A)$ angiographic analysis preoperatively, during hemodynamic collapse, and after intracoronary nitroglycerin $(N T G)$.

$0.8 \%$ to $4.4 \%$ of coronary artery bypass grafting (CABG) operations $^{1-3}$ and typically presents with ST-segment changes, ventricular arrhythmias, or cardiogenic shock during separation from cardiopulmonary bypass. In one study coronary vasospasm accounted for nearly a third of cases of sudden circulatory collapse after CABG. ${ }^{1}$ Coronary artery vasospasm after $\mathrm{CABG}$ appears to have an association with variant angina and preoperative vasospasm. ${ }^{1,2}$

Although postoperative vasospasm has been widely reported after $\mathrm{CABG}$, it is a very rare complication after valvular operations, with only 12 cases reported in the world's literature. Nearly all accounts of coronary spasm after either $\mathrm{CABG}$ or valve surgery describe clinical evidence of ischemia or circulatory collapse during or shortly after separation from cardiopulmonary bypass. However, our patient's ischemia and circulatory collapse occurred at an interval beyond 24 hours from her operation in the absence of any clear physiologic stimulus. This delayed presentation might be attributable to withdrawal from her oral long-acting nitrate and calcium antagonist medications, which were last administered on the morning of her operation.
Although the reported mortality of coronary vasospasm after CABG was $50 \%$ in a series published in $1981,{ }^{1}$ this condition can be treated successfully provided there is early recognition and immediate institution of specific treatment. ${ }^{2}$ Our patient's diffuse and profound coronary vasospasm was successfully treated with IABP support, intracoronary nitrate injection, cessation of adrenergic agonists, and intravenous nitroglycerin. The availability of open-chest intraoperative coronary angiography, which was performed in our hybrid operating room, firmly established the diagnosis and allowed immediate directed therapy.

In conclusion, coronary artery vasospasm can occur after any cardiac operation, is predisposed by clinical features of variant angina, and might be precipitated by withdrawal from long-acting calcium antagonists or nitrates. Successful treatment begins with early recognition and angiographic evaluation, followed by intracoronary nitroglycerin administration, the cessation of adrenergic medications, and the use of intravenous vasodilators. A hybrid operating room-catheterization laboratory is the ideal venue for the evaluation and treatment of patients with early cardiovascular collapse after cardiac surgery. The hybrid setting allows for the assessment of coronary vessels and grafts for injury, thrombosis, or 
vasospasm and provides for immediate percutaneous or surgical therapy.

\section{References}

1. Buxton AE, Goldberg S, Harken AH, Hirschfeld JW, Kastor JA. Coronary artery spasm immediately following coronary artery bypass surgery: recognition and management. N Engl J Med. 1981;304:1249-53.
2. Skarvan K, Graedel E, Hasse J, Stulz P, Pfisterer M. Coronary artery spasms after coronary artery bypass surgery. Anesthesiology. 1984;61:323-7.

3. Watanabe S, Hayashi K, Yamanishi H, et al. Prevention of coronary spasm during and shortly after coronary revascularization in patients with variant angina [in Japanese]. Kyobu Geka. 1994;47(9):723-9.

\title{
Anomalous left coronary artery origin from the opposite sinus of Valsalva: Evidence of intermittent ischemia
}

\author{
Julie Brothers, $\mathrm{MD},{ }^{\mathrm{a}}$ Chris Carter, $\mathrm{MD},{ }^{\mathrm{a}}$ Michael McBride, $\mathrm{PhD},{ }^{\mathrm{a}}$ Thomas Spray, $\mathrm{MD},{ }^{\mathrm{b}}$ and
} Stephen Paridon, MD, ${ }^{\text {a }}$ Philadelphia, $\mathrm{Pa}$

Although a rare anomaly, anomalous aortic origin of a coronary artery that courses between the great vessels (AAOCA) is the second leading cardiovascular cause of death in young athletes. ${ }^{1-3}$ Common presenting symptoms include chest pain, dizziness, and syncope during or just after exertion; however, patients may also have no symptoms, which makes the diagnosis challenging. ${ }^{1-4}$ After diagnosis, most patients undergo provocative ischemia testing with

\footnotetext{
From the Divisions of Cardiology ${ }^{\mathrm{a}}$ and Cardiothoracic Surgery, ${ }^{\mathrm{b}}$ The Children's Hospital of Philadelphia and the University of Pennsylvania, Philadelphia, Pa. Disclosures: None.

Received for publication April 14, 2009; accepted for publication June 10, 2009; available ahead of print Aug 31, 2009.

Address for reprints: Julie Brothers, MD, Cardiology, Main Building, 8NW75, The Children's Hospital of Philadelphia, 34th St and Civic Center Blvd, Philadelphia, PA 19104 (E-mail: brothersj@email.chop.edu).

J Thorac Cardiovasc Surg 2010;140:e27-9 $0022-5223 / \$ 36.00$

Copyright (c) 2010 by The American Association for Thoracic Surgery doi:10.1016/j.jtcvs.2009.06.029
}

an exercise stress test. We present the case of a 13-yearold boy with anomalous left coronary artery arising from the opposite sinus of Valsalva (ALCA), with evidence of ischemia on stress electrocardiography (ECG) on one occasion and a normal stress ECG several days later.

\section{CLINICAL SUMMARY}

A 13-year-old boy came to our Exercise Physiology Laboratory for evaluation of exercise-induced asthma. On a submaximal exercise stress test, significant ST-segment depression was noted in the inferior and lateral ECG leads but resolved during recovery (Figure 1). The boy had no symptoms during the test. In the past, he had reported chest tightness with exercise, which had been attributed to asthma. He returned the next day for a clinic visit. Results of physical examination were unremarkable, and his resting ECG was normal. His transthoracic echocardiogram was indicative of ALCA. Cardiac magnetic resonance imaging confirmed the diagnosis,

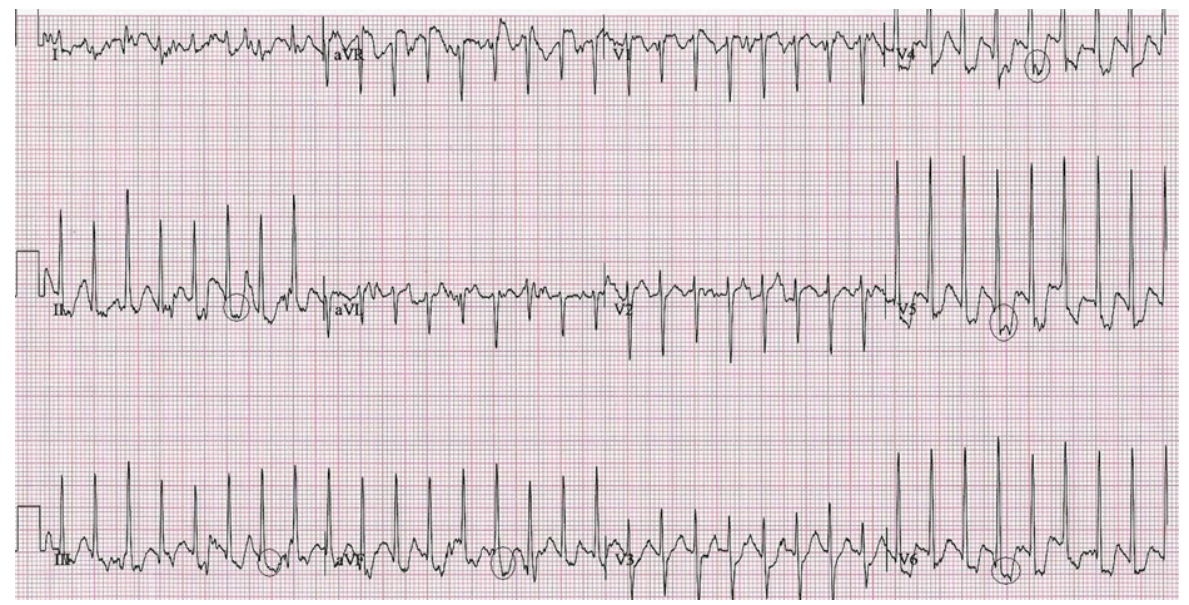

FIGURE 1. Electrocardiogram from submaximal exercise stress test on treadmill shows inferior and lateral lead ST-segment depression. 